\section{Anatomical Differences of the Donkey, Mule, and Horse: An Analysis Relevant to Veterinary Medicine}

\author{
1 Unidad Académica de Anatomía, Facultad de Veterinaria, Universidad \\ de la República, Montevideo, Uruguay \\ ${ }^{2}$ Faculdade de Medicina Veterinária e Zootecnia, Universidade de São \\ Paulo (USP), São Paulo, Brasil
}

* Correspondência: anderson.fs@usp.br

Submetido: 30 jun 2021 | Aprovado: 22 jul 2021

DOI: http://dx.doi.org/10.7213/acad.2021.19601

Rev. Acad. Ciênc. Anim. 2021;19:e19601

A literatura veterinária recebe mais uma grande contribuição, a publicação do livro "Anatomical Differences of the Donkey, Mule, and Horse. An Analysis Relevant to Veterinary Medicine" (Diferenças anatômicas do asno, do muar e do cavalo. Uma análise relevante para a medicina veterinária, em tradução livre). Este livro é o primeiro trabalho a descrever a anatomia aplicada das espécies domésticas da família Equidae. Devido à rusticidade, os asininos e muares tiveram grande importância econômica como animais de carga em muitos países de topografia montanhosa, em áreas de mineração e de difícil acesso. Nos últimos anos, muitos destes animais foram mantidos como animais de estimação nos países ocidentais e usados para fins recreativos e turísticos. Na América do Sul, esses animais são comuns e ainda muito utilizados, sendo que no Brasil estima-se que existam aproximadamente 822.255 e 1.252 .029 cabeças de asininos e muares respectivamente.

\author{
William Pérez (1) 1 \\ Anderson Fernando de Souza (10 ${ }^{2 \star}$
}

Esses animais também necessitam de assistência veterinária e, para tanto, é preciso um conhecimento anatômico sólido. Atualmente, além da escassez de textos científicos sobre anatomia de muares e asininos, não existia até então nenhum livro que contemplasse as espécies citadas de forma comparativa. Esta edição em inglês corresponde à tradução do original (em alemão) publicado um ano antes, intitulado: "Unterschiede in der Anatomie von Esel/Muli und Pferd Eine veterinärmedizinisch Zusammenstellung".

Este livro foi produzido por especialistas em anatomia equina: o Prof. Horst Wissdorf, que de 1972 a 1996 foi diretor do Departamento de Embriologia e Anatomia Aplicada da Universidade de Medicina Veterinária de Hannover, Alemanha, e é autor de outro livro sobre anatomia equina ("Praxisorientierte Anatomie und Propädeutik des Pferdes"; Anatomia orientada para a prática e propedêutica do cavalo, em tradução livre) e o Prof. Hassen Jerbi, anatomista veterinário da Tunísia com expressiva atuação científica na atualidade e que realizou a maior parte das dissecações apresentadas no livro.

O objetivo do livro é descrever as diferenças anatômicas por meio de descrições concisas, juntamente com imagens de peças anatômicas e de animais vivos. Este livro contém 142 páginas distribuídas em 16 capítulos (disponíveis na versão impressa e digital), nos quais são descritos todos os sistemas orgânicos dos muares e asininos, destacando as principais diferenças com os cavalos. 
Para os interessados em aprofundar os conhecimentos sobre estes animais, uma lista de referências bibliográficas é fornecida no final do livro. O texto, muito breve, é muito bem ilustrado, destacando as diferenças e implicações práticas: a inserção de uma sonda nasogástrica; injeções e coletas de sangue da veia jugular externa; a pele como órgão; diferença nos sinais vitais, como temperatura, sons cardíacos, frequência respiratória, etc.

O livro complementa de forma significativa $\mathrm{O}$ conhecimento contido em livros especializados em anatomia, propedêutica e clínica de equinos, e não apenas relevantes para veterinários e estudantes de veterinária, mas também de interesse para proprietários e criadores.

Wissdorf $H$, Jerbi $H$, Meier-Schellersheim M. Anatomical Differences of the Donkey, Mule, and Horse: An Analysis Relevant to Veterinary Medicine. Munique, Alemanha: utzverlag GmbH; 2021. 142 p. ISBN 978-3-8316-4873-3.

\section{Anatomical Differences of the Donkey, Mule, and Horse}

\section{An Analysis Relevant to}

Veterinary Medicine

Horst Wissdorf, Hassen Jerbi, Miriam Meier-Schellersheim
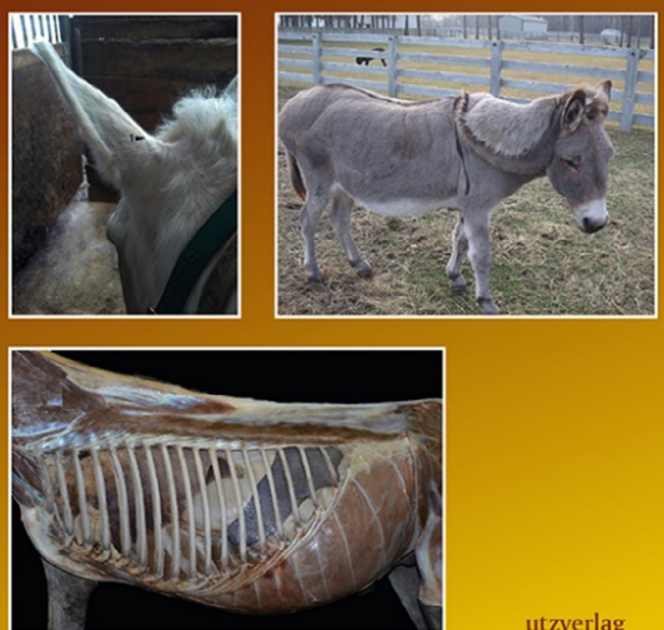

utzverlag 